\title{
Struktur Pesan pada Interactive Voice Response (IVR)
}

\author{
Winangsari Pradani \\ Program Studi Teknik Elektro, Fakultas Sains dan Teknologi, \\ Universitas Al Azhar Indonesia, Jl. Sisingamangaraja, Jakarta 12110 \\ Tel. 7244456, fax. 7244767, email : winangsari@uai.ac.id
}

\begin{abstract}
Interactive Voice Response (IVR) is an automated telephony system that interacts with callers, gathers information and routes calls to the appropriate recipient. An IVR system (IVRS) accepts a combination of voice telephone input and touch-tone keypad selection and provides appropriate responses in the form of voice, fax, callback, e-mail and perhaps other media.

In recent years, many enterprises use IVR as their customer service media. Some problems arise as user problems, that is user have to remembering the too many choices; user does'nt achieve what they want (did not find the right choices); and the worst is tiring finding choices yet they have not find the human operator.

This paper will observe the effect of message structuring for IVR customer satisfication. Human information processing (especially audio-based information) theory as well as menu organizing theory will be used as analysis fundamentals. Questionnaire will be distributed to IVR users to grab the real user experience.
\end{abstract}

Keywords - Interactive Voice Response (IVR), human-computer interaction, audio-based information processing, menu structure, short term memory

\section{PENDAHULUAN}

I nteractive Voice Response (IVR) adalah sebuah system teleponi yang berinteraksi dengan pemanggil, mengumpulkan informasi dan menyalurkan panggilan tersebut ke penerima yang cocok. Sebuah system IVR menerima kombinasi masukan suara telepon dan pilihan tombol-tombol pesawat telepon dan memberikan respons dalam bentuk suara, fax, callback, e-mail dan media lainnya. Sebuah system IVR terdiri atas peralatan telephony, aplikasi software, sebuah basisdata dan infrastruktur pendukung. [1]
Pada saat ini, banyak perusahaan besar menggunakan IVR sebagai customer service. Beberapa masalah layanan IVR perusahaanperusahaan ini yang dirasakan adalah :

- user seringkali harus mengingat pilihan yang banyak;

- user tidak mendapatkan pilihan menu yang cocok dengan permasalahannya;

- Tidak ada fasilitas 'back' ke menu di atasnya jika sampai akhir dialog user tidak menemukan menu yang cocok untuk dipilih; jadi user harus kembali ke menu awal

- User harus mendengar iklan-iklan yang cukup lama dulu sebelum system memberikan pilihan menu

- dan yang paling buruk adalah setelah lelah mencari pilihan, operator manusia juga tidak tersedia, pulsa telah banyak terbuang.

Menghadapi persoalan ini tentu pertanyaan yang muncul adalah : Apakah ada cara penstrukturan pesan yang baik sehingga pemanggil tidak dikecewakan terlalu banyak, dan perusahaan pun mendapatkan reputasi yang baik jika pemanggil (client) puas.

Paper ini akan meneliti sejauh mana pengaruh struktur pesan yang dimasukkan kedalam IVR terhadap kepuasan user. Beberapa teori terkait meliputi pemrosesan informasi oleh manusia khususnya short term memory untuk pengolahan informasi suara (audio), dan tentu saja teori pengorganisasian pilihan (menu). Kuestioner akan disebarkan untuk user para pemakai IVR beberapa perusahaan terkenal. Kemudian hasilnya akan dibandingkan dengan bunyi teori yang telah ada.

Penelitian ini akan mencari jawaban untuk pertanyaan-pertanyaan yang telah dikemukakan di bagian Latar Belakang di atas.

a. Seberapa banyak otak manusia rata-rata dapat mengingat pilihan yang disuarakan,

b. Bagaimana caranya pemanggil mengetahui bahwa pertanyaannya ada atau tidak ada di dalam menu 
c. Jika menu distrukturkan menggunakan struktur pohon, berapa dalam (deep) dan berapa lebar (broad) struktur yang dianggap ideal ?

d. Berapa durasi waktu yang ideal untuk menyuarakan satu pilihan ?

e. Jenis suara apakah yang lebih disukai pemanggil ? apakah suara wanita atau pria?

Keluaran yang diharapkan dari penelitian ini adalah usulan perbaikan terhadap struktur pesan yang didapat dari call-center perusahaan-perusahaan terkenal.

\section{TEORI DASAR}

\subsection{Tipe Interaksi}

Terdapat 4 tipe interaksi dasar antara pemakai dan produk / system. [2]

a. Memerintah - pengguna memberikan perintah kepada system. Ini dapat dilakukan dengan beberapa cara : mengetik perintah, memilih pilihan dari menu yang tersedia, memerintah dengan suara, menekan tombl, dll.

b. Mengobrol - pengguna berdialog dengan system

c. Memanipulasi - pengguna berinteraksi dengan objek dengan cara memanipulasinya.

d. Mengeksplorasi - pengguna bergerak di dalam lingkungan virtual atau tempat fisik.

\subsection{Cognition}

Cognition adalah apa yang berlangsung pada kepala kita (pikiran) ketika kita melakukan aktivitas sehari-hari. Cognition melibatkan proses-proses cognitive seperti berpikir, mengingat, belajar, berkhayal, membuat keputusan, melihat, membaca, menulis, dan berbicara. Sebuah system yang sukses adalah system yang berbasis model konseptual yang sejalan dengan proses cognitive penggunanya. [2]

\subsection{Pemrosesan Informasi melalui Pendengaran}

Auditory processing telah didefinisikan sebagai kemampuan untuk menahan, mengalirkan, dan memroses secara akurat apa yang didengar. Terdapat banyak aspek pada pemrosesan auditori. Ini mencakup kemampuan seperti auditory localization, auditory discrimination, auditory sequencing, auditory figure - ground perception; dan auditory closure. [4]

\subsection{Short-Term Auditory Memory}

Salah satu aspek pemrosesan auditory adalah penahanan informasi agar informasi itu dapat dikenali kata-nya dan dipahami artinya. Penahanan informasi auditori ini seringkali disebut sebagai 'short-term auditory memory'. Kapasitas STAM ini meningkat sejalan dengan meningkatnya usia anak. [4]

Pada orang dewasa pengguna system IVR yang pilihannya dibacakan, menurut Ben Schneiderman [1], user harus membandingkan setiap pilihan yang diberikan dengan sasaran mereka dan menempatkannya dalam suatu skala dari tidak cocok hingga sangat cocok. Satu disain meminta user untuk menerima atau menolak tiap pilihan dengan langsung (segera), sementara disain yang lain membolehkan user untuk memilih setelah semua pilihan dibacakan. Mengulangi daftar pilihan dan sebuah mekanisme keluar haruslah disediakan (lebih baik lagi apabila ada deteksi bahwa pemakai tidak melakukan apa-apa)

Struktur menu yang kompleks harus dihindari. Sebuah petunjuk yang sederhana adalah membatasi jumlah pilihan hingga 3 atau 4 saja untuk menghindari problem mengingat, tetapi aturan ini juga harus di re-evaluasi untuk aplikasi-aplikasi tertentu. Sebagai contoh, system informasi bioskop akan lebih berguna kalau menggunakan daftar yang panjang dari semua film yang diputar di sana daripada memecah daftar film itu menjadi kelompok-kelompok. Fasilitas dial-ahead (memutar duluan) memungkinkan pengguna ulang melompati prompt yang ada. Sebagai contoh, pengguna menu telepon apotik mungkin masih ingat bahwa mereka dapat menekan 1 diikuti 0 untuk menghubungi langsung apotekernya tanpa harus menunggu pesan selamat datang dan daftar pilihan.

\subsection{Menu berstruktur pohon}

Kedalaman, atau jumlah level pada sebuah pohon menu bergantung pada kelebaran atau jumlah pilihan per level. Jika lebih banyak pilihan diberikan di menu utama maka pohonnya melebar dan memiliki sedikit level. Bentuk ini memberikan keuntungan jika pilihan-pilihan itu jelas. Beberapa penulis membatasi 3 sampai 4 pilihan per menu, tetapi pada saat yang sama mereka juga membatasi jumlah level 3 sampai 4. Pada aplikasi dengan banyak pilihan, kedua aturan ini harus dikompromikan.

Beberapa studi empiris telah dilakukan untuk menemukan kompromi kedalaman dan kelebaran, 
dan ternyata kelebaran lebih disukai daripada kedalaman. Memang ada alasan disainer untuk membatasi pohon menu menjadi 3 level : jika kedalaman mencapai 4 atau 5, pengguna menjadi disorientasi (kehilangan arah). Jacko dan Salvendy (1996) menemukan bahwa waktu respons dan jumlah error meningkat seiring dengan semakin dalamnya pohon menu.

\subsection{Waktu Respons dan Ekspektasi Pengguna}

Terdapat 3 faktor primer yang mempengaruhi ekspektasi dan perilaku user berkaitan dengan waktu respons :

a. Pengalaman sebelumnya : Jika sebuah task selesai lebih cepat dari ekspektasi, orang akan senang, namun jika selesainya task tersebut jauh lebih cepat, orang akan merasa bahwa yang dikerjakan kemungkinan salah. Sama juga jika task jauh lebih lambat selesai, pengguna akan cemas atau frustasi. Walaupun orang dapat mendeteksi $8 \%$ perubahan pada waktu respons 2-4 detik, orang masih dapat menerima sampai perubahan itu lebih besar lagi.

b. Perbedaan karakter pengguna

c. Perbedaan task

Perbedaan individu begitu besar dan pengguna itu adaptif. Mereka akan bekerja lebih cepat jika telah berpengalaman dan akan mengubah strategi kerja mereka sewaktu waktu respons berubah. Mungkin berguna jika pengguna dapat menge-set kecepatan interaksi mereka sendiri.

Untuk pekerjaan berulang, pengguna lebih suka bekerja lebih cepat.

Untuk pekerjaan yang kompleks, pengguna dapat beradaptasi untuk bekerja dengan waktu respons yang lebih lambat tanpa kehilangan produktifitasnya, tetapi pengguna akan tidak puas jika waktu respons meningkat.

\section{PEMBAHASAN}

\subsection{Kinerja IVR}

Dalam penelitian ini akan diamati kondisi call center yang ada dari 2 kelompok perusahaan besar yakni :

1. Kelompok Perusahaan Penyedia Jasa Telepon Seluler

2. Perusahaan Bank
Untuk kelompok Penyedia Jasa Telepon Seluler dipilih 2 perusahaan yang memiliki konsumen yang cukup banyak, yakni XL dan Indosat. Sedangkan untuk Bank dipilih Bank Mandiri

Untuk kelompok Penyedia Jasa Telepon Seluler dipilih 2 perusahaan yang memiliki konsumen yang cukup banyak, yakni XL dan Indosat. Sedangkan untuk Bank dipilih Bank Mandiri

Kinerja system IVR akan dinilai dari :

1. Kedalaman dan Kelebaran pohon menu : Menurut teori di bab 2 di atas, kedalaman pohon sebaiknya dibatasi hingga 4 , sedangkan kelebaran yang ideal adalah juga 3 - 4. Terlalu dalam pengguna akan tersesat, terlalu lebar pengguna akan mengingat terlalu banyak.

2. Terdapat mekanisme pengulangan pilihan dan mekanisme back dan exit

3. Tersedia mekanisme memutar duluan (dialahead)

4. Respons time

5. Menyediakan operator manusia

Tabel 1 Kinerja Sistem IVR beberapa perusahaan

\begin{tabular}{|c|c|c|c|c|c|c|c|}
\hline No & $\begin{array}{l}\text { Ukuran } \\
\text { Kinerja }\end{array}$ & \multicolumn{2}{|c|}{ IVR - XL } & \multicolumn{2}{|c|}{ IVR - Indosat } & \multicolumn{2}{|c|}{ IVR - Mandiri } \\
\hline \multirow[t]{10}{*}{1.} & $\begin{array}{l}\text { Struktur } \\
\text { Pohon Menu }\end{array}$ & & & & & & \\
\hline & Kedalaman & \multicolumn{2}{|c|}{6 level } & \multicolumn{2}{|c|}{6 level } & \multicolumn{2}{|c|}{3 level } \\
\hline & Kelebaran & \multicolumn{2}{|c|}{6} & \multicolumn{2}{|c|}{9} & \multicolumn{2}{|c|}{9} \\
\hline & \multirow[t]{7}{*}{$\begin{array}{l}\text { Panjang path } \\
\text { ke setiap } \\
\text { pilihan akhir }\end{array}$} & $\begin{array}{l}\text { Jum- } \\
\text { lah } \\
\text { level }\end{array}$ & $\begin{array}{l}\text { Jum- } \\
\text { lah } \\
\text { pilih } \\
\text { an }\end{array}$ & $\begin{array}{l}\text { Jum- } \\
\text { lah } \\
\text { level }\end{array}$ & $\begin{array}{l}\text { Jum- } \\
\text { lah } \\
\text { pilih } \\
\text { an }\end{array}$ & $\begin{array}{l}\text { Jum- } \\
\text { lah } \\
\text { level }\end{array}$ & $\begin{array}{l}\text { Jum- } \\
\text { lah } \\
\text { pilih } \\
\text { an }\end{array}$ \\
\hline & & 3 & 2 & 2 & 1 & 2 & 29 \\
\hline & & 4 & 5 & 3 & 1 & \multirow[t]{5}{*}{3} & \multirow[t]{5}{*}{20} \\
\hline & & 5 & 4 & 4 & 15 & & \\
\hline & & & & 5 & 44 & & \\
\hline & & & & 6 & 91 & & \\
\hline & & & & 7 & 7 & & \\
\hline 2. & $\begin{array}{l}\text { Mekanisme } \\
\text { Pengulangan } \\
\text {, back, exit }\end{array}$ & \multicolumn{2}{|c|}{$\begin{array}{l}\text { Ada, tapi tidak } \\
\text { di setiap level }\end{array}$} & \multicolumn{2}{|c|}{ Ada } & \multicolumn{2}{|c|}{ Ada } \\
\hline 3. & Dial-ahead & \multicolumn{2}{|c|}{ Tidak ada } & & & \multicolumn{2}{|c|}{ Tidak ada } \\
\hline 4. & Respons time & \multicolumn{2}{|c|}{ Baik } & \multicolumn{2}{|c|}{$\begin{array}{l}\text { Di beberapa } \\
\text { lokasi terdapat } \\
\text { pembacaan } \\
\text { informasi } \\
\text { promosi } \\
\text { (berkisar } 30 \text { - } \\
60 \text { detik) } \\
\text { sebelum } \\
\text { penelepon } \\
\text { mengetikkan } \\
\text { pilihan }\end{array}$} & \multicolumn{2}{|c|}{ Baik } \\
\hline 5. & $\begin{array}{l}\text { Operator } \\
\text { Manusia }\end{array}$ & \multicolumn{2}{|c|}{$\begin{array}{l}\text { Tidak tersedia } \\
\text { di menu }\end{array}$} & \multicolumn{2}{|c|}{$\begin{array}{l}\text { Tidak tersedia } \\
\text { di menu }\end{array}$} & \multicolumn{2}{|c|}{ Tersedia } \\
\hline
\end{tabular}

Dari tabel 1 di atas terlihat bahwa dari ketiga perusahaan tersebut, yang memiliki 3 level hanya IVR - Bank Mandiri, sedangkan kedua IVR Perusahaan mobile memiliki struktur pohon yang cukup dalam. Dari kelebaran, IVR-2 dan IVR-3 memiliki 9 pilihan yang berarti pengguna harus ekstra keras mengingat pilihan yang dia cari. 


\subsection{Perilaku Responden}

- Sebanyak $60 \%$ responden akan menghubungi customer service jika mengalami masalah pada produk yang mereka miliki.

- Sebagian besar responden (84\%) pernah menghubungi customer service.

- Responden lebih suka menghubungi customer service lewat telepon (70\%), walaupun mereka memiliki akses internet.

- Alasan tidak pernah menghubungi call center kebanyakan adalah karena merasa rumit.

- Dalam 6 bulan ini, 64\% pengguna menelepon call center satu kali

- Perusahaan yang dihubungi oleh responden yang terbanyak adalah perusahaan telepon (92\%), setelah itu rumah sakit dan bank

- Responden kebanyakan menghubungi customer service berkaitan dengan keluhan layanan (72\%)

- Responden menelepon sesingkat mungkin (maks 5 menit)

- Tingkat kepuasan responden terhadap waktu telepon bervariasi, ada yang puas dan ada yang tidak puas dengan jumlah seimbang

- Menurut responden, durasi telepon yang ideal adalah antara 6 sampai 10 menit.

- Ternyata hanya $20 \%$ responden yang merasa puas terhadap layanan call center. Yang lainnya sebanyak $64 \%$ tercapai apa yang dicari namun merasa butuh waktu terlalu lama. Sebanyak $16 \%$ tidak tercapai apa yang diinginkan.

- Jika menghubungi call center, para responden kebanyakan (94\%) lebih suka terhubung dengan operator manusia langsung.

- Alasan mereka lebih suka operator manusia adalah karena merasa lebih mudah dan juga melalui mesin penjawab terlalu lama.

- Sedangkan yang lebih suka dijawab oleh mesin penjawab adalah karena lebih sederhana, tinggal menekan pilihan yang tersedia.

- Menurut responden, waktu call yang terlalu lama adalah akibat terlalu panjangnya iklan.

- Sebanyak $74 \%$ responden tidak puas dengan biaya pelayanan call center.

- Seluruh responden menginginkan gratis jika menghubungi call center.

- Para responden ingin mendapatkan informasi pelayanan call center melalui $\mathrm{TV}$, internet, reklame, dan poster.

\section{KESIMPULAN DAN SARAN}

\subsection{Kesimpulan}

Dari ketiga perusahaan yang diteliti, yang memiliki 3 level hanya IVR - Bank Mandiri, sedangkan kedua IVR Perusahaan mobile memiliki struktur pohon yang cukup dalam. Dari kelebaran, IVR-2 dan IVR-3 memiliki 9 pilihan yang berarti pengguna harus ekstra keras mengingat pilihan yang dia cari.

Dari kuestioner yang dibagikan kepada 50 orang responden didapat bahwa :

- Responden kebanyakan menghubungi customer service lewat telepon walaupun mereka memiliki akses internet. Artinya jika sistem IVR sebuah perusahaan disusun dan dirancang dengan baik maka user akan merasa nyaman dan pada akhirnya akan loyal pada suatu produk.

- Hingga saat ini, untuk mendapatkan informasi yang diinginkan dari sebuah call center atau IVR, user harus berkorban dengan waktu pelayanan yang panjang akibat struktur pohon terlalu dalam dan atau pembacaan promosi (rata-rata 40 detik). Ihwal pembacaan promosi ini alih-alih berpromosi, user malah tidak mendapatkan kesan yang baik dari pelayanan ini.

- Sebenarnya user suka pada pilihan yang simpel yang dibacakan pada IVR, namun akibat pengalaman yang buruk pada penggunaan sistem ini sebelumnya, maka user lebih suka menghubungi operator manusia, padahal operator manusia merupakan biaya yang mahal dari operasional layanan.

\subsection{Saran}

Struktur menu IVR sebaiknya disusun ulang agar kedalaman maupun kelebarannya mengikuti teori; Pembacaan promosi fitur sebaiknya dihindari kecuali user yang meminta sendiri (hal ini dapat disiasati dengan memberikan menu promosi sendiri). 


\section{DAFTAR PUSTAKA}

[1] Andrew J. Waite, "Customers : Arriving with a History Leaving with an Experience! How to build your Sales, Service or Helpdesk Call Center to Please Customer", Telecom Books, New York, 1996

[2] Beatrice Mense, Sue Debney and Tanya Druce, "Short-term Auditory Memory Activities, Ready Set Remember", ACER Press Australian Council for Educational Research Ltd, 2006
[3] Ben Shneiderman \& Catherine Plaisant, "Designing the User Interface : Strategies for Effective Human-Computer Interaction", $5^{\text {th }} \mathrm{ed}$, Addison Wesley, Pearson, 2009

[4] Helen Sharp, Yvonne Rogers, Jenny Preece, "Interaction Design, Beyond Human-Computer Interaction", $2^{\text {nd }}$ ed, John Wiley \& Sons, 2006

[5] http://www.bitpipe.com/tlist/IVR.html tanggal 28 Des 09 